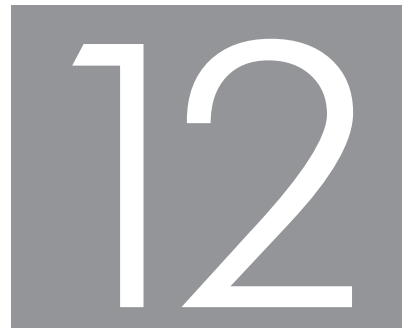

\title{
THE PROFESSIONAL \\ DEVELOPMENT OF ACADEMICS
}

\section{IN PURSUIT OF SCHOLARSHIP}

\section{Liezel Frick \& Chris Kapp}

\section{ABSTRACT}

In this chapter we explore the development of academic staff as an area or theme for study and research in the field of higher education - from both a theoretical and a practical stance. We start by providing a broad definition and an overview of a number of theories underlying the concept and continue to discuss the issues and challenges that it faces in higher education. The notion of scholarship forms the basis of the discussion. A brief discussion on how academic professional development is practised ensues and a South African case study of formal education for academic professional development and the scholarship of teaching is explored. We conclude this chapter with a number of ideas on future developments in the field, which may be of interest to scholars who wish to study the professional development of academics within institutions of higher education.

\section{INTRODUCTION}

Higher education worldwide has been experiencing change at a rate unknown in the past and several chapters in this book highlight this reality. The so-called knowledge society and information age within which we live are characterised by an increased rate of knowledge production and greater access to information. Universities are experiencing this information boom in many ways, but the most significant changes affecting higher education have been dealt with by transforming the system. New types of institutions have emerged, new academic programmes have developed, the traditional disciplinary approach has been questioned, and learning has been transformed by new technologies. The drive for transformation has also led to a questioning of what universities do and how well they are doing it (the drive for quality). 
The academic staff member stands at the centre of all these changes. Despite all the transformative changes attacking the "soul" of the university (Levine 2000), academic staff have had to continue with their scholarly business: teaching, research and interaction with communities. University lecturers as professionals function within a unique area of professional practice, as their practice requires elements of both discipline-specific and educational expertise. Academic professional development (APD) has emerged as an area of practice (and study) in higher education as a way in which to help academic staff to adapt and to keep abreast of all these changes and challenges.

This chapter provides a conceptualisation and overview of APD and explores the rationale for engaging in APD initiatives. A comparative case study of two South African programmes aimed at developing the scholarship of teaching is used to illustrate a formal approach to APD. We conclude by considering APD as a field of study. An overview of scholarly research contributions to the area of APD illustrates the interests and approaches of scholars interested in the study of APD. This synthesis allows us to consider the way forward for APD as an area of study.

\section{THE PROFESSIONAL DEVELOPMENT OF ACADEMICS: DEFINITION AND UNDERLYING THEORIES}

Academic professional development (APD) is not easily defined, and scholars need to take heed of various related and underlying terms and theories in the study of such a phenomenon. For the purposes of this book it was consciously decided to use the term 'academic professional development' rather than related terms such as 'continuing professional development' (CPD), 'continuing professional education' $(\mathrm{CPE})$, 'continuing professional learning' (CPL) or 'staff development' (which could include employees of the university at all levels), as the chapter specifically focuses on lecturers as professional practitioners in academia. APD is seen as the broadest possible concept that incorporates both the education and learning that academics as professionals engage in during their transition from novices to experts and beyond. (This would include self-directed and informal learning experiences, as well as formalised and non-formal learning.)

Why the emphasis on development? Webb (1996:65, in Land 2001:4) describes development as a contestable and non-unitary concept, and therefore "of necessity a site for encounter and dispute". As such, development goes further than education (the transfer of knowledge and/or skills through various means in its broadest sense) 
and learning (incorporating education into existing knowledge and/or skill systems). Development includes incorporating and adapting all that is learnt (in whichever way) into professional practice, making it appropriate to the individual professional's context. Professional development stretches beyond knowledge and skills to the values and attitudes that define an individual's professional identity as a scholar. It also places greater emphasis on the organisation than on the individual in terms of needs, purposes and provision of development initiatives. Therefore APD is seen as more appropriate in the higher education context as it implies a holistic approach to learning, transformation and application that takes place within the total context of academics' professional practice. APD includes the actions, activities, policies and procedures that an institution puts in place to ensure the continuous professional growth and development of its most expensive and precious commodity, namely its academic staff. In the context of this book APD can therefore be defined as any formal, non-formal or informal initiative beyond initial training whereby the lecturer as professional practitioner obtains knowledge and/or skills that can transform professional practice and/or professional identity. APD refers to the enhancement of professional competence and expertise to the benefit of the individual professional, the organisation, its clients and society as a whole (see Frick and Kapp 2007 for a more detailed discussion).

The work environment in academic practice makes diverse demands on the lecturer as a professional practitioner. These demands can be summarised according to the various scholarship roles (discovery, teaching, engagement and integration) initially defined by Boyer (1990) and later expanded by various authors (O'Meara and Rice 2005; Badley 2003; Sorcinelli 2002; Zahorski 2002; Rice 1991, 1996, 2002; Diamond 1993, 1999; Lynton and Driscoll 1999; Schulman 1999; Lynton 1995 -amongst others). Lynton (1995) and Lynton and Driscoll (1999) later added the scholarship of engagement. The four scholarly roles of Boyer (1990) will be used as a basis for the arguments posed in this chapter. Boyer's (1990) dimensions of scholarship provide a mandate for APD, as academic renewal (and therefore APD) is essential to the life of the university. What it means to conduct scholarly work in academe will be discussed in greater depth in some of the other chapters in this book.

The idea of APD therefore needs to be placed within the context of academic practice and the notion of scholarship for the purposes of this chapter. Scholarship is determined by having scholarly credentials within a specific discipline (usually by means of research), staying abreast of the latest developments in a field, maintaining the standards of integrity of a discipline (thus refraining from any unethical behaviour), and through the assessment of scholarly work in whichever form (often through 
publication and peer review). Glassick, Huber and Maeroff (1997) translate these scholarly prerequisites into more definite criteria for scholarly practice, namely clear goals, adequate preparation, appropriate methods, significant results, effective presentation, and reflective critique. These criteria apply to all activities deemed as scholarly - be it discovery (research), teaching, engagement (service) or integration. Boyer (1990) concludes that a delicate balance exists between systematic rigour and flexibility in the assessment of scholarship.

Scholarship is a multidimensional concept and the scholar is expected to negotiate what Barnett (2000, in Harris 2005:426) describes as "dynamic relationships between social and epistemological interests and structures". Scholarly identity is a product of individual values and beliefs, as well as institutional culture and positioning of the particular discipline. Developing a scholarly identity has become increasingly difficult in an academic environment that places multiple demands on the scholar (Harris 2005), in an environment where research is seen as "the strongest academic currency in higher education" (Henkel 2005: 164). Scholarly development and identity therefore tend to focus on the scholarship of discovery in a specific discipline (Andresen 2000).

Very few lecturers excel naturally and equally in all their scholarship roles (Andresen 2000). The majority of lecturers need to continuously develop their professional skills in all their scholarly roles. An integrated model of academic professional practice in higher education is therefore implied, which integrates the lecturer's scholarly roles of teaching, research, engagement, integration and administration. This is in contrast to a more one-dimensional model, where the academic practitioner would focus on only one of these roles and develop linearly within the specific role. McDonald (2001), Kachingwe (2000) and Cobb (1999) point out the difficulty in developing, integrating and balancing these roles and responsibilities in practice. The question is whether academic professional development can be seen as a coping mechanism for modern-day lecturers in their constant quest for professional balance and excellence as scholars.

\section{A BRIEF HISTORY OF ACADEMIC PROFESSIONAL DEVELOPMENT}

The period 1979-2000 was characterised by a search for a definition, a context, a purpose and a philosophy of APD. The first documented and purposeful attempt to define the concept and to describe the context, purpose and philosophy of APD was made by an international group of 'new' so-called staff developers from 30 countries at a workshop on Staff Development that was sponsored by the British Council and 
held at Oxford University from 1-12 April 1979. These staff developers came from a diverse range of disciplines, although most of the early leaders in APD came from a teaching and learning (education) background (especially in South Africa), which may have influenced the evident emphasis on the scholarship of teaching and learning in APD. This initial workshop was facilitated by Alan Harding (an engineer) and the proceedings of the workshop captured perspectives from all the participating countries. The participants eventually defined APD, then referred to as staff development, as "all actions, activities, procedures and policies that an institution puts in place to enhance the performance and productivity of their staff" (Harding, Kaewsonthi, Roe and Stevens 1981). The consensus on the purpose of staff development was that it would improve and develop the quality of teaching and learning in higher education by providing a support service to academic staff.

From a South African perspective, the lead in establishing APD as an area of practice and later as an area of study within higher education was taken by Kalie Strydom from the University of the Free State, who called the first conference on this topic in 1979. The movement towards establishing APD units was triggered by several government reports that expressed concern about the high failure rate of first-year students and put the blame for this partially on the lack of teaching skills of academic staff (also see the chapter by Bitzer and Wilkinson). The main activities of these units in South Africa were similar to those in other countries, as the focus of the majority of units (called bureaus) was mainly on curriculum design, teaching and learning, and assessment. This included induction courses for new academic staff, skills-based workshops on aspects related to teaching and learning, consultation services to individual staff members, student feedback and related activities and policy development.

The representatives from South African APD units (bureaus) regularly met as most of them represented their institution on a sub-committee for university teaching of the Committee of University Principals (CUP). It was from these meetings and the conferences arranged by Strydom that the South African Association for Research and Development (SAARDHE) was established in 1979. One of the first objectives of SAARDHE was to establish an academic journal, the South African Journal of Higher Education, in 1987.

A later international survey by Frick and Kapp (2006a) revealed a number of significant changes that took place between 1995 and 2005. The main change in APD was reportedly the change in the profile of APD. The acceptance of continuing professional development (CPD) in APD (even replacing academic staff development in terms of 
accepted terminology in some cases) was also noted within the responses of APD managers, whereas the past revealed a 'train and release' approach - as stated by one respondent. Changes in reports and policies seem to have had a determining effect on the practice of APD in higher education. Examples of these changes include the Dearing Report in the UK (National Committee of Enquiry into Higher Education 1997), a move to outcomes-based education (OBE) in South Africa (RSA 1996), New Zealand's Education Amendment Act (New Zealand Government 1990). A progressive move to learner-centred education and teaching has required a change in APD, and e-learning has necessitated an informed input from the APD sector. The increase in demands placed on academic staff in higher education has also influenced the practice of APD. Other noted changes include changes in the strategic positioning of APD within institutions, and more specialised input that is required into the key focus areas of APD, such as research specialisation and e-learning as well as policy changes towards outcomes-based education. The main trend observed in the particular study was related to the focus of APD centres/units, which remained strongly linked to improving teaching. This emphasis on the scholarship of teaching and learning in institutionalised APD was clearly illustrated by the names given to or adopted by most of the units.

\section{THE RATIONALE FOR ACADEMIC PROFESSIONAL DEVELOPMENT}

Professionals do not have the luxury of predictable career paths in the postmodern organisation. Grzyb, Graham and Donaldson (1998) found that career instability was a determining factor in professionals' decisions to participate in APD activities. Technological advances and changes in student demographics add to the changed (and still changing) academic context within which academic professionals have to function. Within the South African context the digital revolution with its emphasis on e-learning, the diversity of student populations and academic staff after 1994, the move towards outcomes-based education and the initial introduction of the National Qualifications Framework (NQF) and later the Higher Education Qualifications Framework (HEQF) formed part of this changing context. Continuous research and debate in the field of scholarship development is necessary to understand the current context of academic practice and help shape its future. The need for APD is therefore not just to keep abreast of the latest developments, but also to improve the continuing employability of professionals (Kabouridis and Link 2001; Kachingwe 2000; SadlerSmith, Allinson and Hayes 2000; Challis 1999; Grzyb et al. 1998). 
Professionals seek APD as additional educational experiences to remind them of what they once knew and have forgotten (affirm and refresh), to acquaint them with the latest developments in knowledge (update) and to help them solve problems (reflect and apply). APD is a vital instrument through which professionals can channel their creative energy, talents and skills in order to remain relevant in society and continue to be viable in the profession. The learning in APD can either be incremental, which refines or adds to past learning, or transformational, which is new and fundamentally different from previous learning. Each individual therefore makes a unique combination of theory and practice (Alemna 2001; Beatty 2001; Daley 2001; McDonald 2001).

APD is also influenced by the organisation. This leads to the central problematic question surrounding APD: Whose interests are being served by APD? The conflict between the self-fulfilment of the individual professional and the expectations of the organisation is integral to the different purposes stated in the literature on APD (McDonald 2001; Wilson 2000; Battersby 1999). Grzyb et al. (1998) found that organisations use subtle ways to exercise power over professionals, including power over the decisions to participate in APD. The role of organisational context in APD is becoming increasingly important. Performance and learning take on multiple forms within organisations and are influenced by the context, the organisational setting and the learners' personal motivation, job satisfaction, morale and activity. Socialisation of professionals into practice tends to be founded on the organisation rather than on the profession itself, as the organisation creates the social and structural context of successful professionalisation (Hart et al. 2000; Knox 2000; Odini 1999; Bitzer and Kapp 1998; Grzyb et al. 1998). Livneh and Livneh (1999) support the influence of external motivators, referring to organisational influences such as promotion and remuneration in the professional's decision to pursue APD. Internal motivation, however, remains the strongest force in the professional's quest for further education.

The interplay between individual and organisational interests raises questions on whether professional development (generally speaking) should be of a compulsory nature. The need for such development can also be approached from other perspectives, such as legislative forces, where accreditation and certification play determining roles in the APD sphere. McDonald (2001) and Mott (2000) specifically refer to increased public pressure and demand for recertification and even relicensure for professionals. Globally, governments have turned to professional credentials in ensuring professional competence, establishing standards of practice, protecting public interests and maintaining minimum levels of ethical practice. Mandatory professional development as a means of maintaining credentials remains an unresolved issue. Critics argue 
that it leads to higher costs to the consumer and is based on a remedial approach to education, whilst there is no evidence that mandatory initiatives ensure professional competence. Current assessment or evaluation methodologies cannot ensure that mandatory professional development will lead to improved or maintained competence (McDonald 2001 ; Daley 2000).

Lecturers in higher education, more specifically, are faced with a unique situation due to the multifaceted nature of their practice. The academic culture often places a higher value on scientific knowledge and research skills than on other forms of scholarship (Daley 2001; McDonald 2001). The segmentation of knowledge into sequential, discipline-specific credit units has made the integration of scholarship roles even more difficult. In order to adhere to the demands of this knowledge-based curriculum, these lecturers lose touch with the practice for which they are supposed to prepare prospective professionals. McDonald (2001), however, warns that lecturers should not become estranged to the realities of practice. Lecturers in higher education are often caught between advancing their own careers within the academic sphere and preparing their clientele for professional practice (Daley 2001; McDonald 2001). In academe, this means developing as a scholar in research, teaching and engagement. Lecturers as academics are therefore expected to maintain expertise within their specific field of practice, and they need to understand the pedagogy of conveying this expertise to their students and the wider community. Learning - as an essential component of scholarly development - is then envisioned as a transforming process for all concerned, rather than a mere transfer of information. This is increasingly difficult in a system that places diverse demands on its members in terms of research, teaching, engagement, integration and administration.

Challis (1999) summarises these different perspectives into three broad purposes of APD: firstly, it is the updating of knowledge and skills in existing and new areas of practice; secondly, it is the preparation for a changing role in the organisation, new responsibilities and promotion; thirdly, it increases competence in a wider context with benefits to both professional and personal roles. Cervero (2000) concludes that the bottom line of APD is to improve practice, whatever it entails.

\section{MODELS AND APPROACHES}

APD models and approaches need to be placed against a contextual backdrop. Aspects such as institutional culture (Land 2001) and the influence of academic tribes and territories (Becher and Trowler 2001) provide the growth medium for APD within the 
wider higher education climate. Academic practice in higher education is multifaceted and it is influenced by a multitude of contextual changes. Higher education institutions in South Africa have had to deal with changes in context, such as globalisation, massification of the education system that has led to a more diverse learner population, diminishing resources, demands for quality, responsiveness and accountability and greater competition among institutions of higher education (Boughey, in Gravett and Geyser 2004; Quinn and Vorster 2004). Land (2004) concurs that massification has changed the higher education landscape and influenced the growth in APD. He adds that managerialism in higher education and the pressures for accountability, the increase in learning technologies, marketisation and consumerism, as well as pedagogic and epistemic changes have also influenced models and approaches to APD. The type and amount of work required from lecturers in higher education have changed considerably as a result of these contextual changes. Lecturers are increasingly required to professionalise their practice as educators, carry larger administrative loads and achieve higher standards with fewer resources as a result of downsizing, mergers and/or financial constraints (Boughey, in Gravett and Geyser 2004). This frequently requires role changes in terms of the lecturers' scholarly responsibilities, for which they are often ill prepared. Higher education institutions locally and abroad expect lecturers to excel in their scholarly roles, but the extent to which the institution itself engages in the APD of lecturers is changing.

Land (2004) accordingly describes different stances academic developers may have towards change. These include diffusion, systemic, rationality, motivational, power, dialectical, bricolage, ambiguity and contingency stances. Land (2001, 2004) furthermore argues that academic developers' stances towards change may influence their orientation to APD and consequently describes 12 such possible orientations: managerial, political-strategic, entrepreneurial, romantic (or ecological humanist), opportunist, researcher, professional competence, reflective practitioner, internal consultant, modeller-broker, interpretive-hermeneutic, and provocateur (disciplinespecific). These orientations refer to academic developers' attitudes, knowledge, aims and tendencies for action in relation to contextual practices and challenges (see Land $2001: 6,19$ for more detailed descriptions). Land (2004) concludes that variations of these stances and orientations may exist. The interplay between stance and orientation will obviously have an influence on the models and approaches employed within a particular institution. Land's (2001:9) perspective is useful as it theorises APD as an interplay between a systems/person focus on the one axis, and domesticating/liberating 


\section{PART FOUR - TESTIMONIES AND REFLECTIONS ON PROFESSIONAL DEVELOPMENT}

focus on the other. APD can therefore be positioned according to the institutional culture as

- anarchic (a liberating, person-centred culture);

- collegial (a more person-oriented environment that balances domesticating and liberating influences);

- enterprise (a liberating focus in a systems-oriented environment);

- hierarchical (a person orientation, within a domesticating environment);

- managerial (a systems orientation with a domesticating focus), or

- political (with a balance between all four above-mentioned institutional foci).

McNay's (1995) model of universities as organisations is of particular interest here, since universities seem to have moved towards more corporate or corporation modes of policy definition and implementation. This trend is also evident in the way in which APD is practised. Both Boughey (2004, in Gravett and Geyser 2004) in the South African context and Cervero (2001) in the United States of America context indicate an increase in the decentralisation of APD. Traditional providers of higher education, such as universities, can no longer ignore the corporate sector as a determining role-player in the provision of APD to academic staff. APD has become part of an education-forprofit trend. Current competition among professional associations, higher education institutions, business and industry and entrepreneurial agencies has resulted in a variety of APD programmes that are offered simultaneously to lecturers within universities. Each of these providers promotes his/her programme as timely, relevant and of the highest quality. The lack of established international educational standards for APD programmes offered to lecturers makes it nearly impossible to make an informed choice from all the offerings. A more integrated approach is called for, which will support dialogue, collaborative inquiry, research that is sensitive to practice, and improved learning and practice. This will contribute to growth and sustainability within the area of APD and bridge possible gaps between initial theoretical education and practice in professions (Daley 2001; McDonald 2001; Cervero 2000; Daley and Mott 2000; Knox 2000; Castle, Holloway and Race 1998). Properly planned and monitored collaboration and integration between APD providers (both internal and external to the university) should not be seen as a threat to the university in terms of academic professional development. Outsourcing certain aspects of APD offered to lecturers to private providers may lead to further collaborative opportunities as well as to the incorporation of specific expertise otherwise unavailable to the academic sector, which could benefit all stakeholders and contribute to the development of scholarship in all its facets. 
Higher education institutions, however, continue to play an important role in the continuous development of their academic staff through institutional units or centres aimed at increasing staff competence for the institutional good. Frick and Kapp (2006a) provide an international view on the past, present and future in APD with a particular focus on institutional centres or units. Frick and Kapp (2006a) found that the strategic positioning of APD within institutions is mainly within the academic realm, although some reported a more non-academic/administrative positioning. As could be expected, the main focus seemed to be on the scholarship of teaching, and more particularly on e-learning and the use of technology, assessment, curriculum review, the promotion of student-centred approaches to teaching, skills development (writing and library skills development) and distance education. General support in the areas of policy development and implementation, research, quality promotion, transformation, provision of funding, development of management skills and academic integrity were noted to a lesser extent. Support for the induction of new academic staff seem to be an important focus area in APD, while more advanced academic staff seem to receive less focused attention. Involvement in staff performance management is an interesting focus area that warrants further investigation. How the support in the focus areas takes place seemed to vary among workshops, qualification-based initiatives, discussions/ forums, lectures/presentations and individual consultations.

The main challenges that managers in APD reportedly have to face include a lack of resources, achieving buy-in from all stakeholders, gaining support from senior management, achieving an equitable balance between teaching and research in the higher education environment, managing their staff and the centre/unit as a whole, dealing with a lack of understanding for educational principles in the higher education environment in general, dealing with institutional pressures, coping with the divergent needs of the clientele, dealing with policy, assessing academic professional development output in a sensible manner, effectively positioning the centre/unit strategically, and combating low morale amongst lecturers (Frick and Kapp 2006a). The data in the particular study revealed that several of the centres/units were not aligned to the institutional direction and were going off on their own tangents. There may have been several reasons for this trend. One could be that institutions did not always have clarity on their direction and did not have a clear vision of the role and function of APD within their institutions. A second reason for this lack of alignment may be related to the first. Because of a lack of direction from the institutional leadership, directors of APD units developed their own niche and moved in a direction they thought was appropriate. In some cases units were closed down after national reviews. 
Major changes in the staffing and functioning of these units could also be attributed to changes in institutional leadership. Name changes (such as in the case of the Learning Support Network) indicate a change in focus from teaching to learning and from giving direction to supporting and from a unit to a network. This may align such centres/units more closely to institutional mission statements and a broader conceptualisation of scholarship roles. Several cases were found where units were linked to information technology, although there were institutions where no such link existed. One significant shift that could be observed was one away from a generic approach to APD to the use of practitioners - in many cases subject experts who had a proven success record in their fields of expertise.

Moyo, Donn and Hounsell (1997) found that lecturers themselves are ready and willing to adopt new coping strategies in higher education. They see APD programmes as a way to cope with the changes and transitions that are eminent in the South African higher education arena. The challenges presented to lecturers have led to the introduction of accredited professional development courses for academics by means of formal qualifications. The need for increased professionalisation within education calls for a clear articulation of qualifications that includes formal education and acknowledges prior experiences or learning (Shah 1998; Florez 1997). Quinn and Vorster (2004) recommend a strong and well-articulated theoretical foundation for APD programmes for lecturers. Quinn and Vorster (2004), Moyo et al. (1997), Brew (1995) and Murray (1995) furthermore emphasise the importance of support if academic practices are to change in an ongoing and meaningful manner. Castle et al. (1998) stress the importance of recognition of prior learning for those professionals who have already achieved a certain level of expertise and competency. Constructing a professional identity for lecturers in higher education has, however, been problematic in terms of control over the production of and access to knowledge and the establishment of formal qualifications. Apart from the normal academic qualifications in higher education in South Africa, there is currently no general mandatory professional certification or requirement that guards entry and continuing practice as an academic (although specific professions, such as nursing, do have more structured systems in place).

Moyo et al. (1997) support the introduction of an accredited, award-bearing programme in South African higher education as part of APD for lecturers in higher education, while Åkerlind (2007) notes an increase in compulsory teaching courses and/or qualifications for lecturers in higher education in the United Kingdom. Formal APD seems to centre on the development of teaching as a scholarly endeavour, while the development of other scholarly roles seems to be self-initiated and informal. Quinn 
and Vorster (2004) explain that the emphasis on the scholarship of teaching and learning is necessary since the traditional lecture format does not seem suitable any longer. They also argue that lecturers need to cultivate a spirit of lifelong learning in their learners and therefore lecturers and their learners need to be actively engaged in the learning process. Brew (1995) adds that accreditation can serve to recognise and reward development initiatives formally. Åkerlind (2007:34), however, notes negative reactions of academics towards compulsory initiatives aimed at improving teaching in higher education:

Of course, any compulsory course is likely to put academics off, but this only partially explains the negative reaction of some participants. An additional explanation is that academics who believe that the best route to improving teaching is to focus on becoming more familiar with what and how to teach, through increasing content knowledge and acquiring practical experience ... must logically see no purpose to such courses [in reference to compulsory courses aimed at improving teaching]. From this perspective, staying in touch with the research literature in their field and gaining teaching experience would always be seen as more valuable for teaching development. The particular perspective would also lead to the common argument that experience as a teacher makes participation in such courses redundant.

However, Akerlind (2007:34-35) goes further to explain that there are lecturers who view educational programmes or courses as a way in which to develop as scholars of teaching. It is therefore essential for any formal programme aimed at enhancing teaching expertise to aim at finding the nexus between lecturers' understanding of what it means to develop as a teacher, and what academic developers (as facilitators of these programmes) view as teaching development (Åkerlind 2007). Åkerlind (2007) concludes that, in order to be effective, any teaching development initiative needs to be tailored to individual academics' intentions and understandings of teaching and teaching development. This means that either the development support provided should be closely aligned to these lecturers' understandings, or that their understandings have to be expanded in order for a broader range of support initiatives to be adopted.

The following comparative case study of two South African programmes aimed at developing the scholarship of teaching is used to illustrate a formal approach to APD. Quinn and Vorster (2004) propose the Postgraduate Certificate in Higher Education and Training (PGCHET) as one example of an option to encourage and develop critical reflection on teaching. Quinn and Vorster (2004) describe the PGCHET (referring to the format presented at Rhodes University) as a practice-based course that facilitates 
the professional development of lecturers in terms of learner assessment, evaluation of own practices, developing knowledge within the field of higher education and providing professional accreditation. A complementary programme to the PGCHET could be the MPhil (Higher Education) offered by the Centre for Higher and Adult Education at Stellenbosch University. These two qualifications are compared in Table 12.1. (A list of formal qualifications in the area of higher education studies in South Africa appears in Annexure 17.4 of the chapter by Bitzer and Wilkinson.)

Table 12.1 indicates that the two qualifications are comparable in terms of most aspects. There is, however, a difference in HEQF levels and subsequently possible further studies. The PGCHET is at an honours level (HEQF level 8) and therefore leads to a master's or equivalent qualification in comparison to the MPhil (Higher Education), which is at a master's level (HEQF Level 9) and can therefore lead to a PhD degree. Table 12.2 compares these two qualifications in terms of structure and credit values.

It is clear that the PGCHET is highly comparable to the MPhil (Higher Education). The thesis component in the latter programme makes the main difference in the research emphasis and total credit values, and therefore also in the possibilities for further study.

In terms of international comparability of the PGCHET, the Staff and Educational Development Association (SEDA) of Great Britain developed a scheme as late as 1994 that sets benchmarks for the area of academic professional development. The scheme is based on the submission of a portfolio of evidence (similar to that required in the PGCHET in South Africa) that might be accredited towards a Fellowship or an Associate Fellowship (the latter having only one third of the portfolio size of the former). The SEDA qualification is highly comparable to the PGCHET in terms of its standards and core objectives. However, the PGCHET includes additional aspects relevant to the South African context, such as a core unit standard on mission, policies and legislation. Furthermore, the PGCHET contains specific elective unit standards (such as Web-based learning and Experiential Learning and Supervising Research), which are indirectly addressed in the British SEDA (ETDP SETA 2003).

The PGCHET is comparable to Australia's Prompts for Good Practice (ETDP SETA 2003), which is published by the Higher Education Research and Development Society of Australasia (HERDSA). It consists of collections of questions on the roles of the higher education educator. These roles are similar to those that give structure to the PGCHET. The PGCHET's unit standards and core objectives also compare favourably to the prompts given in the above-mentioned publication, which forms the basis for the 
development and certification of higher education professionals in Australasia (ETDP SETA 2003).

Professional practice in higher education in the USA has been greatly influenced by the Seven Principles for Good Practice in undergraduate education (Chickering and Gamson 1987). These principles are based on a synthesis of decades of relevant research and provide guidelines for the development of higher education professionals. The principles can be closely associated with the unit standards and core objectives of the PGCHET. There are, however, no cited university programme qualifications in the USA that are directly comparable to the PGCHET. Most of the programmes that are offered are at master's and doctoral level and focus on administration, student affairs, leadership, policy studies, student development or counselling and research (ETDP SETA 2003).

Quinn and Vorster (2004) concluded that encouraging lecturers to reflect critically on their practices, to examine the epistemologies underlying their disciplines and the implications thereof for teaching and learning, and introducing them to a variety of theoretical frameworks can change their conceptions of teaching. However, these authors also warn that course facilitators of this type of APD programme should understand the factors that inhibit or prevent lecturers from implementing new ideas and developing their professional practice in terms of teaching competence.

Attaining a qualification does, however, not guarantee that competence or expertise will be maintained. The actual practice of APD in maintaining competence needs more investigation, especially in terms of the link between professional work, constructivist learning and transformative learning. APD providers often assume that the simple transmission of information in the educational setting will influence practice, yet Ryan, Campbell and Brigham (1999) report that research results regarding the effect of APD on behavioural change have not been consistent. It cannot be assumed that APD will have a positive effect on practice. APD is only effective in terms of the extent to which it is implemented in practice and the outcomes can be assessed. Variables, including both individual and organisational variables, need to be considered to determine why behavioural change does or does not occur.

Wenger's (1998) work on communities of practice makes an important contribution to the understanding and support of APD within higher education institutions. The components of a social theory of learning that form the basis for Wenger's (1998:5) notion of communities of practice include the elements of meaning (how individuals and/or groups communicate on understanding the world and essentially what is 


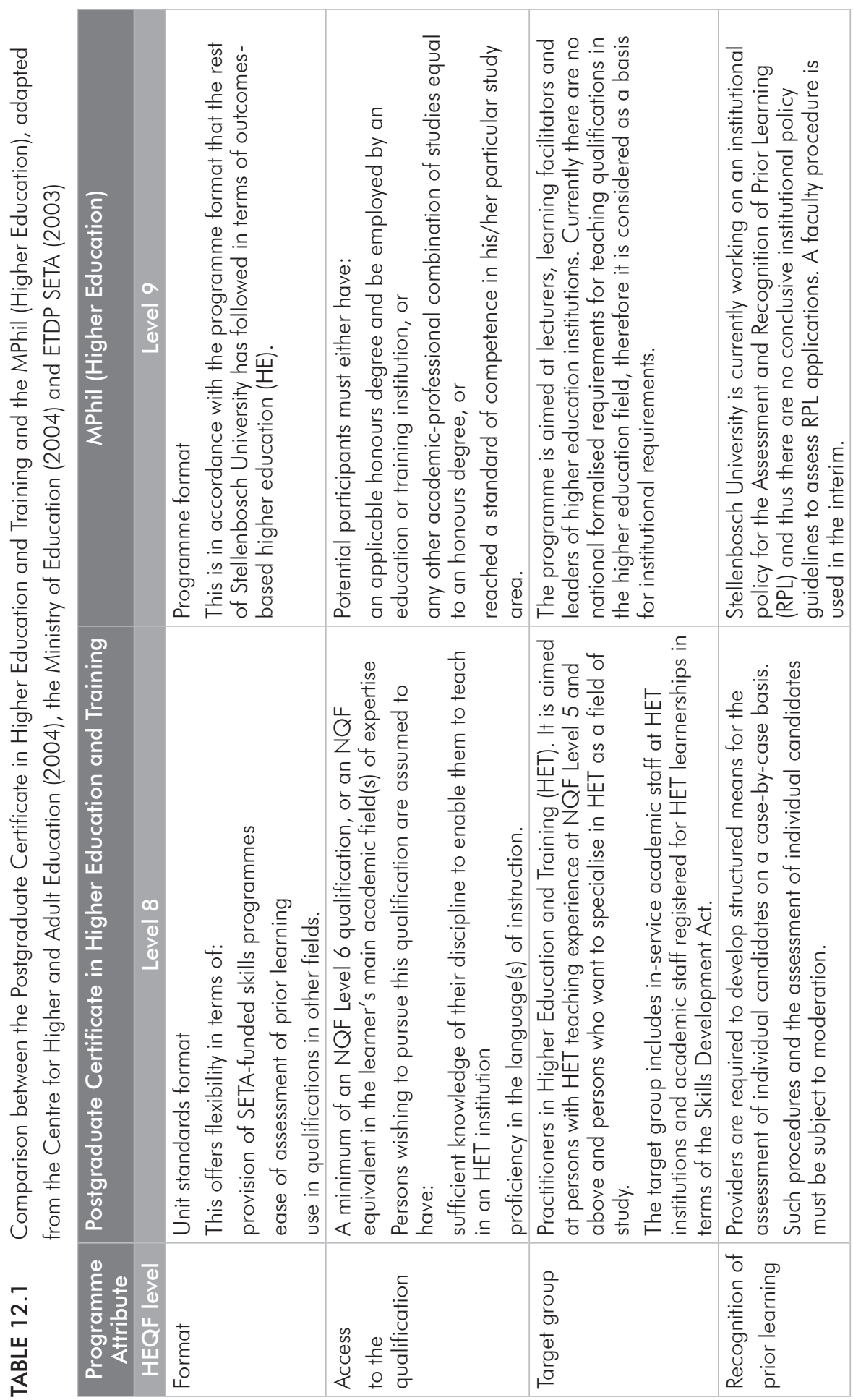




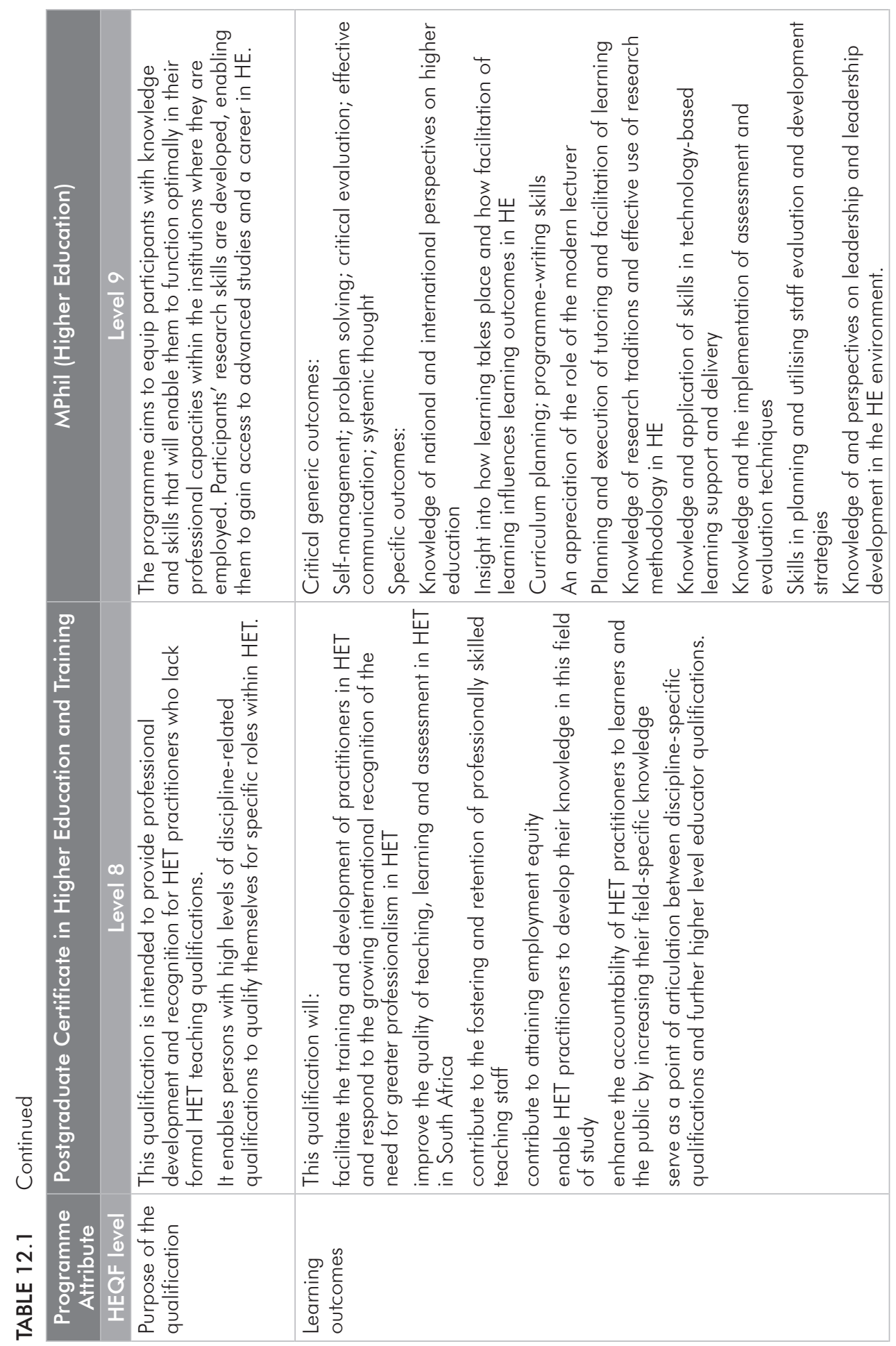




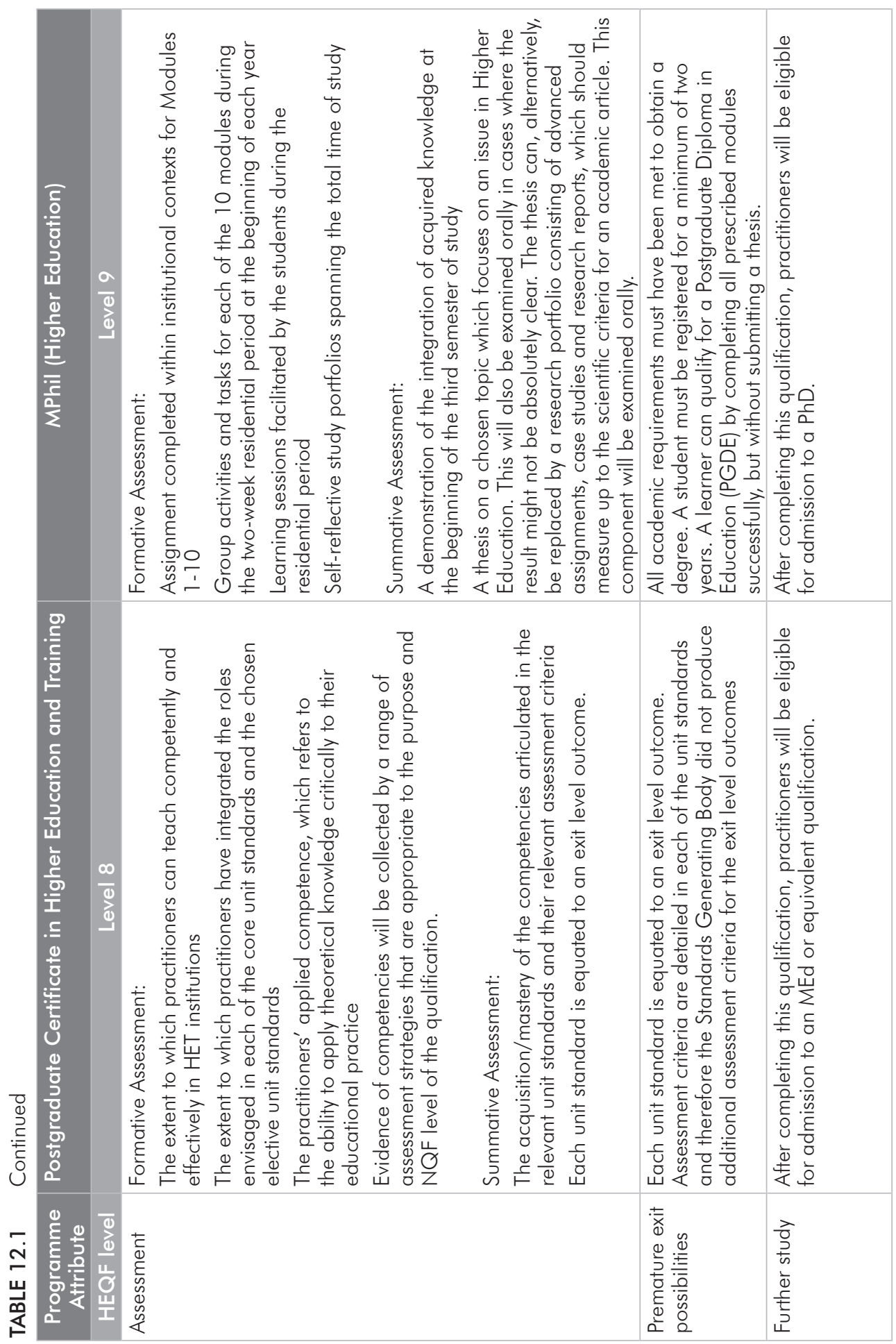


TABLE 12.2 Comparison between the Postgraduate Certificate in Higher Education and Training and the MPhil (Higher Education) in terms of structure and credit values, adapted from ETDP SETA (2003) and the Centre for Higher and Adult Education (2004)*

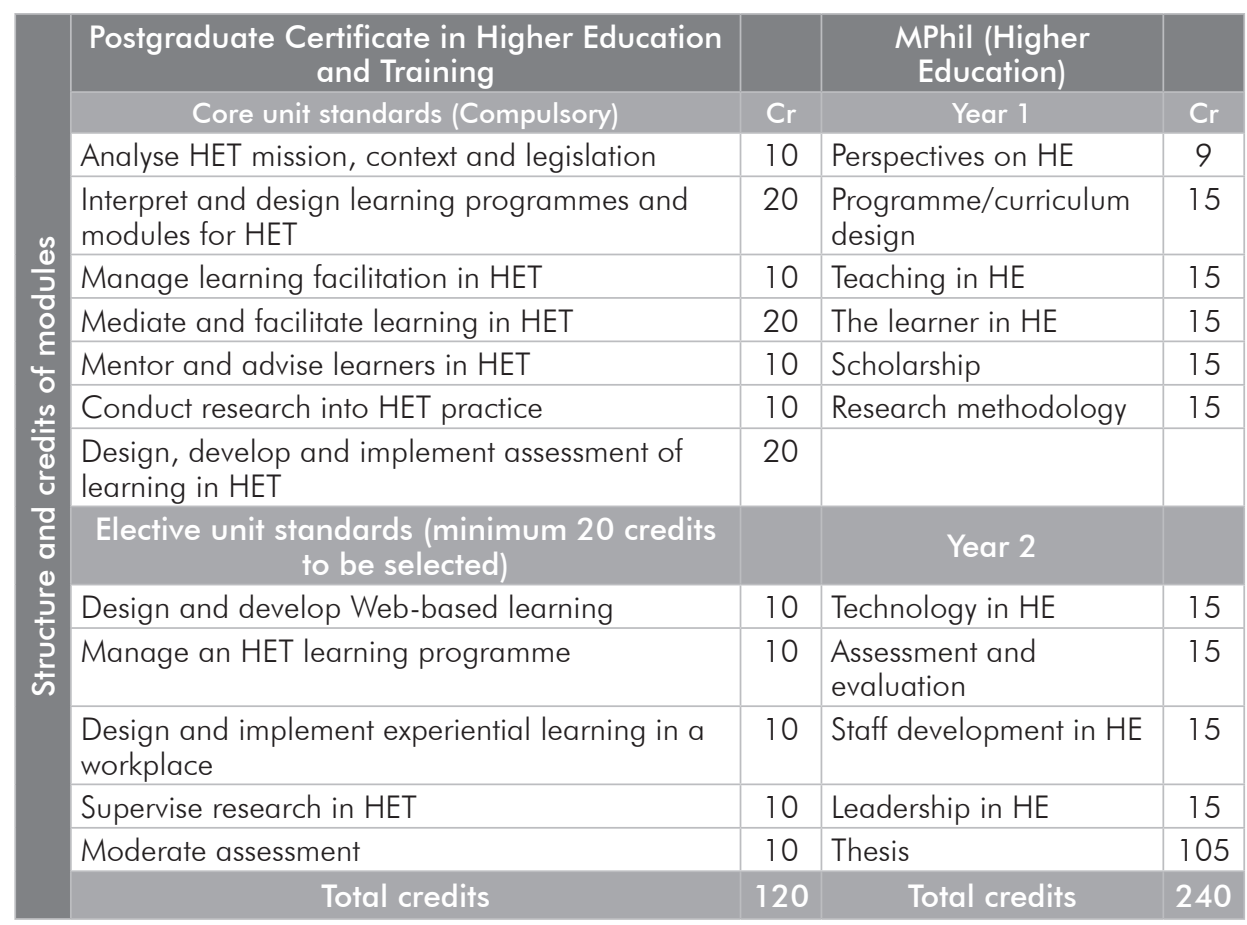

* For the latest information on the MPhil (Higher Education) see www.sun.ac.za/chae

considered as meaningful), practice (the sharing of historical and social resources, frameworks and perspectives that can sustain all stakeholders' engagement in action), community (with reference to specific social configurations that influence what is seen as worthwhile actions and within which competence is defined and recognised), and identity (how learning leads to change and creates personal histories of becoming in the context of a particular community) ${ }^{1}$. Communities of practice can be facilitated by creating shared spaces for critical discourse - for example, conference participation, tearoom discussions, interdisciplinary research groups, journal clubs, regular seminars, and mentoring programmes. These spaces are to serve as a place of belonging and a sounding-board for scholars (Christiansen and Slammert 2006; Johnson 2006; Sorcinelli 2002). Henkel (2005) adds that the proliferation of research centres and institutes as structures that cut across disciplinary divides is evidence of a more networkbased approach to academic practice and scholarly development. 


\section{SCHOLARLY RESEARCH CONTRIBUTIONS TO THE AREA OF ACADEMIC PROFESSIONAL DEVELOPMENT}

What does the future hold for APD as a field of study? A synthesis of the literature reveals that APD is a complex and ever-evolving area of practice in higher education. Input from a variety of countries indicates an initial shift from an instructional approach to a more strategic and facilitative one. There seems to be a focus on developing the scholarship of teaching and learning, even though a broader perspective on the scholarship of teaching is evident which integrates research-based practice and a lifelong learning orientation.

There is an impressive body of literature on APD from scholars in a variety of countries. Several country-specific perspectives, as well as international perspectives, are to be found in the recorded literature. Most of these have been published in academic journals such as the International Journal for Academic Development. Looking at the literature more or less chronologically, one of the first publications on the topic was the outcome of the 1979 British Council course on Staff Development in Higher Education at Oxford. Harding, Kaewsonthi, Roe and Stevens (1981) refer to the development of professionals in academe as "all activities, actions, processes and procedures that an organisation develops or uses to enhance the performance and the potential of its human resources". Since then several books have been published on the topic, but none of them have attempted to provide a broad overview of the past, present and future of APD. However, these publications have all made significant contributions to the area. Professional development in higher education: A theoretical framework for action research by Zuber-Skerrit (1992) provides an excellent example of scholarly work within APD. Publications by Brew (1995), Webb (1996) and Rowland, Byron, Furedi, Padfield and Smyth (1998) also fall within this category.

In the past couple of years several relevant articles have been published that have made major contributions to the area of APD. Noteworthy contributions from an Australian perspective were produced by Kirkpatrick (2001), Kandlbinder (2003) and Smyth (2003) and from a United Kingdom perspective by Gosling (2001). Sandretto, Kane and Heath (2002) provided insight into APD processes in New Zealand and Canadian authors such as Kreber (2000) and Kreber and Cranton (2000) approached APD from a scholarship perspective.

More recent publications that provide a major overview of past and present APD activities include The Scholarship of Academic Development by Eggins and Macdonald (2003), which can be regarded as the most comprehensive view on APD in recent 
times from a United Kingdom perspective. Also within the United Kingdom, Becher and Trowler (2001) and Bath and Smith (2004) have written about academic tribes and their territories. Macdonald (2005) reports on recent developments in learning and teaching and an article by Blackmore and Wilson (2005) covers problems in APD. APD in the United States of America has received extensive attention, and it is essential to take cognisance in particular of the work done by Lieberman (2005) on centres for teaching and learning as laboratories for learning, and the publication by Sorcinelli, Austin, Eddy and Beach (2006) entitled Creating the future of faculty development: learning from the past, understanding the present, which also provides valuable insights. Harland and Staniforth (2003) provide an international perspective on APD. Jarvis, Kondrashova, Efendiev and Tukhfatullin (2005) report on APD in Russia while Odabasi (2005) contributes an opinion on the status and need for APD in Turkey. Taylor (2005) discusses APD as a part of institutional leadership in Canada.

Contributions to the South African point of view have been sparse. The report by Moyo, Donn and Hounsell (1997) on Academic Development and Strategic Change in Higher Education and a Manual for Staff Developers by Bitzer and Kapp (1998) are noted, as well as some articles on the topic (Volbrecht 2003; Quinn 2003; Frick 2007; Frick and Kapp 2005, 2006a, 2006b, 2006c, 2006d, 2007). The audit completed by Moyo, Donn and Hounsell (1997) on academic development and strategic change in South African higher education may have presented a skewed or limited perspective on APD, as it was approached mainly from a student perspective and not from a staff perspective. Quinn (2003) and Quinn and Vorster (2004) reported on one approach to APD at one university, while Volbrecht (2003) questioned the appropriateness of approaches to APD in South Africa. The work done by Frick (2007) and Frick and Kapp (2005, 2006b-d, 2007) focuses particularly on the CPD of academic staff within the natural sciences at one university.

What does the future hold for APD as an area of study? A synthesis of consulted literature reveals that APD is a complex and ever-evolving area of practice and inquiry in higher education. Developments in a variety of countries indicate an initial shift from an instructional approach to a more strategic and facilitative approach. There also seems to be a broader perspective on the scholarship of teaching which resulted in integrating research-based practice and a lifelong learning orientation. 


\section{CONCLUSION}

APD continues to form an integral part of the higher education system, also in South Africa. Some of the future trends seem to be a continuation of what is presently on the agenda. These include an emphasis on the importance of the context in which the academic professional operates. APD aimed at helping academics cope with the recent and current fast pace of change in the South African national higher education system is at the forefront of national debates. Internationally, as well as locally, the influence of the information age and technology on education systems is receiving much attention. Along with this, a greater emphasis on the scholarship of teaching has been observed. The merging with information technology and consequently a stronger emphasis on e-learning as support will remain an issue. Approaches to the development of academic staff may continue to be less generic and more focused on the discipline, which implies an increase in the involvement of subject experts or practitioners.

In terms of institutional APD structures, evidence suggests that some development units have become too bureaucratic and too much focused on administrative/policy/rules and regulation issues, instead of on academic issues. In the South African context this trend may be explained by the high incidence of post-1994 national policy changes that have necessitated a reinterpretation of institutional policies. A more academic orientation in these units may make it necessary for academic staff of APD units to become more research-oriented. To secure buy-in from academic staff, the focus will have to be on those things valued by staff, such as research. A related challenge concerns the workload of the staff of APD units, and more specifically their career development. The latter is directly related to research, for which staff in APD units will have to find sufficient time.

Although the above does not claim to be comprehensive, some clear trends can be deducted. One trend seems to be the ongoing battle for identity and recognition or 'territory'. Further seemingly valid claims made in the above-mentioned literature include the following:

- $A P D$ seems to have evolved from a singular focus on teaching to an understanding of teaching within a broader framework (the context of the institution), to programme design, to learner-centredness, to networking in communities of scholars, to the integration of technology, and to integrated scholarship. 
- The primary purpose of APD has concurrently shifted, with a sustained emphasis on teaching and even more so on learning, to helping individual staff members to act as change agents.

- The structures for APD seem to remain stagnant, although there are stronger indications of a realisation by institutional leadership of the important roles it has to play in an institution and of the diversity of needs it has to address.

From the above overview it has become clear that there are gaps in the way the field has been covered. Perspectives were perhaps too narrow or too protective, or in some cases too broad. This chapter is an attempt to plot the field, to do a reconnaissance of the field and then to provide possible areas of interest for future research, particularly in the domain of South African higher education studies and research.

\section{REFERENCES}

Åkerlind GS. 2007. Constraints on academics' potential for developing as a teacher. Studies in Higher Education, 32(1):21-37.

Alemna AA. 2001. Perception of continuing education for librarianship in Ghana. New Library World, 102(1 160):44-47.

Andresen LW. 2000. A usable, trans-disciplinary conception of scholarship. Higher Education Research and Development, 19(2):137-153.

ETDP SETA. 2003. Towards learnerships and skills programmes linked to the PGCHET for tertiary educators. Proceedings of the ETDP SETA Workshop. Birchwood Conference Centre. 6-7 August 2003.

Badley G. 2003. Improving the scholarship of teaching and learning. Innovations in Education and Teaching International, 40(3):303-309.

Bath D \& Smith C. 2004. Academic developers: An academic tribe claiming their territory in higher education. International Journal for Academic Development, 9(1):9-27.

Battersby D.1999. The learning organisation and CPD: Some philosophical considerations. The Learning Organization, 6(2):58-62.

Beatty RM. 2001. Continuing professional education, organizational support and professional competence: Dilemmas of rural nurses. The Journal of Continuing Education in Nursing, 32(5):203-209.

Becher T \& Trowler PR. 2001. Academic tribes and territories. Intellectual enquiries and the culture of disciplines. 2nd Edition. Buckingham: Open University Press.

Bitzer EM \& Kapp CA. 1998. A manual for new academic staff developers in further and higher education. Centre for Higher and Adult Education. Stellenbosch: Stellenbosch University.

Blackmore P \& Wilson A. 2005. Problems in staff and educational development leadership: Solving, framing, and avoiding. International Journal for Academic Development, 10(2):107-123. 
Boyer EL. 1990. Sholarship reconsidered: Priorities of the professoriate. Princeton: Carnegie Foundation for the Advancement of Teaching.

Brew A. 1995. Directions in staff development. London: Society for research into Higher Education.

Castle A, Holloway DG \& Race AJ. 1998. A review of issues in continuing professional development in teaching, nursing and radiography. International Journal of Lifelong Education, 17(5):328-340.

Centre for Higher and Adult Education 2004. MPhil (Higher Education) pamphlet. Stellenbosch: Stellenbosch University.

Cervero RM. 2001. Continuing professional education in transition, 1981-2000. International Journal of Lifelong Education, 20(1/2):16-30.

Cervero RM. 2000. Trends and issues in continuing professional education. New Directions for Adult and Continuing Education, 86:3-12.

Challis M. 1999. AMEE Medical Education Guide No. 11 (revised): Portfolio-based learning and assessment in medical education. Medical Teacher, 21 (4):370-386.

Chickering AW \& Gamson ZF. 1987. Seven Principles for Good Practice. AAHE Bulletin, (39):3-7.

Christiansen IM \& Slammert L. 2006. A multi-faceted approach to research development (II): Supporting communities of practice. South African Journal of Higher Education, 20(1):15-28.

Cobb VL. 1999. In international comparison of teacher education. ERIC Digest, ED436486.

Daley BJ. 2000. Learning in professional practice. New Directions in Adult and Continuing Education, 86:33-41.

Daley BJ. 2001. Learning and professional practice: A study of four professions. Adult Education Quarterly, 52(1):39-54.

Daley BJ \& Mott VW. 2000. Continuing professional education: From vision to reality. New Directions for Adult and Continuing Education, 86:80-85.

Diamond RM. 1993. Changing priorities and the faculty reward system. In: RM Diamond \& BE Adam. Recognizing faculty work: Reward systems for the year 2000. San Francisco: Jossey-Bass.

Diamond RM. 1999. Aligning faculty rewards with institutional mission: Statements, policies and guidelines. Bolton: Anker.

Eggins H \& Macdonald R. 2003. The scholarship of academic development. Buckingham: Society for research into Higher Education and Open University Press.

Florez MAC. 1997. The adult ESL teaching profession. ERIC Digest, ED413794.

Frick BL. 2007. The evolution of scholarship in the natural sciences: Providing a framework for Continuing Professional Development (CPD). Centre for Research in Lifelong Learning Conference: Researching transitions in Lifelong Learning, 22-24 June 2007, University of Stirling (Stirling, Scotland). 
Frick BL \& Kapp CA. 2005. Making quality count in continuing professional development. South African Development Association Conference, 28-30 November 2005, Durban Institute of Technology (Durban, South Africa).

Frick BL \& Kapp CA. 2006a. Academic staff development: past, present and future. International Consortium for Educational Development, 11-14 June 2006, Sheffield Hallam University (Sheffield, United Kingdom).

Frick BL \& Kapp CA. 2006b. Future trends in continuing professional development for natural science lecturers in higher education - survival of the fittest in the academic jungle. Teaching and Learning Forum 2006, 1-2 February 2006, University of Western Australia (Perth, Australia).

Frick BL \& Kapp CA. 2006c. Continuing professional development (CPD) of lecturers in the natural sciences: Enhancing the quality of learning. Education as Change, 10(2):81-96.

Frick BL \& Kapp CA. 2006d. Mapping the provision of continuing professional development in the natural sciences in higher education. Acta Academica, 38(2):229-253.

Frick BL \& Kapp CA. 2007. Plotting the playing field for continuing professional development in the natural sciences. South African Journal of Higher Education, 21 (3):443-456.

Glassick CE, Huber MT \& Maeroff GI. 1997. Scholarship assessed. Evaluation of the professorate. San Francisco: Jossey-Bass.

Gosling D. 2001. Educational development units in the UK - what are they doing five years on? International Journal for Academic Development, 6(1):74-90.

Gravett S \& Geyser H. 2004. Teaching and learning in higher education. Pretoria: Van Schaik.

Grzyb SW, Graham SW \& Donaldson JF. 1998. The influences of organizational and demographic variables on participation in continuing professional education. The Journal of Continuing Higher Education, 46(1):2-15.

Harding AG, Kaewsonthi S, Roe E \& Stevens JR. 1981. Professional development in higher education. Bradford, UK: University of Bradford, Educational Development Service.

Harland T \& Staniforth D. 2003. Academic development as academic work. International Journal for Academic Development, 8(1/2):25-35.

Harris S. 2005. Rethinking academic identities in neo-liberal times. Teaching in Higher Education, 10(4):421-433.

Hart G, Clinton M, Edwards H, Evans K, Lunney P, Posner N, Tooth B, Weir D \& Ryan Y. 2000. Accelerated professional development and peer consultation: Two strategies for continuing professional education for nurses. The Journal for Continuing Education in Nursing, $31(1): 28-37$.

Henkel M. 2005. Academic identity and autonomy in a changing policy environment. Higher Education, 49:155-176.

Jarvis DK, Kondrashova MV, Efendiev AG \& Tukhfatullin M. 2005. Faculty development in Russian higher education. International Journal for Academic Development, 10(2):125-137.

Johnson B. 2006. South African academia in crisis: The spread of "contrived collegial managerialism". South African Journal of Higher Education, 20(1):56-69. 


\section{PART FOUR • TESTIMONIES AND REFLECTIONS ON PROFESSIONAL DEVELOPMENT}

Kabouridis G \& Link D. 2001. Quality assessment of continuing education short courses. Quality Assurance in Education, 9(2):103-109.

Kachingwe AF. 2000. Diversity and continuing professional education: Defining and synthesizing. The Journal of Continuing Higher Education, 48(2):28-36.

Kandlbinder, P. 2003. Peeking under the covers: on-line academic staff development in Australia and the United Kingdom. International Journal for Academic Development, 8(1/2):135-143.

Kirkpatrick D. 2001. Staff development for flexible learning. International Journal for Academic Development, 6(2):168-176.

Knox AB. 2000. The continuum of professional education and practice. New Directions for Adult and Continuing Education, 86:13-22.

Kreber C. 2000. How university teaching award winners conceptualise academic work: Some further thoughts on the meaning of scholarship. Teaching in Higher Education, 5(1):61-78.

Kreber C \& Cranton PA. 2000. Exploring the scholarship of teaching. The Journal of Higher Education, $71(4): 476-495$.

Land R. 2001 . Agency, context and change in academic development. International Journal for Academic Development, 6(1):4-20.

Land R. 2004. Educational development. Discourse, identity and practice. Berkshire: Open University Press.

Levine A. 2000. The soul of the new university. New York Times, 13 March 2000.

Lieberman D. 2005. Beyond faculty development: How centres for teaching and learning can be laboratories for learning. New Directions for Higher Education, 131:87-98.

Livneh C \& Livneh H. 1999. Continuing professional education among educators: Predictors of participation in learning activities. Adult Education Quarterly, 49(2):91-106.

Lynton E. 1995. Making a case for professional service. Washington DC: American Association for Higher Education.

Lynton E \& Driscoll A. 1999. Making outreach visible: A guide to documenting professional service and outreach. Washington DC: American Association for Higher Education.

Macdonald R. 2005. Recent developments in learning and teaching in the UK. HERDSA News, April 2005: 18-20.

McDonald C. 2001. A review of continuing professional education. The Journal of Continuing Higher Education, 49(1):29-40.

McNay I. 1995. The Changing University. Buckingham: SHRE and Open University Press.

Merriam SB. 2005. Emerging trends and research in adult learning theory. Presentation at Stellenbosch University. 11 November 2005.

Ministry of Education 2004. The Higher Education Qualifications Framework. Policy issued under the Higher Education Act, Act No. 101 of 1997. Draft for discussion. Pretoria: State Publishers.

Mott VW. 2000. The development of professional expertise in the workplace. New Directions for Adult and Continuing Education, 86:23-31. 
Moyo C, Donn G \& Hounsell D. 1997. Academic development and strategic change in higher education. SAAAD Needs Assessment and Audit of Academic Development in South Africa Report.

Murray JP. 1995. Successful faculty development and evaluation: The complete teaching portfolio. ASHE_ERIC Higher Education Report No. 8. The George Washington University, Graduate School of Education and Human Development. Washington DC.

National Committee of Enquiry into Higher Education. 1997. Higher education in the learning society: Report of the National Committee. London: HMSO.

New Zealand Government. 1990. Education Amendment Act. Wellington: Government Printer.

Odabasi HF. 2005. The status and need for faculty development in Turkey. International Journal for Academic Development, 10(2):139-142.

Odini C. 1999. Training and development of skills in a changing information environment. Library Management, 20(2):100-104.

O'Meara KA \& Rice RE. 2005. Faculty priorities reconsidered: Rewarding multiple forms of scholarship. San Francisco: Jossey-Bass.

Quinn L. 2003. A theoretical framework for professional development in a South African university. International Journal for Academic Development, 8(1/2):61-75.

Quinn L \& Vorster J. 2004. Transforming teachers' conceptions of teaching and learning in a postgraduate certificate in higher education and training course. South African Journal of Higher Education, 18(1):364-381.

Rice RE. 1991. The new American scholar: Scholarship and the purposes of the university. Metropolitan Universities Journal, 1(4):7-18.

Rice RE. 1996. Making a place for the new American scholar. Washington DC: American Association for Higher Education.

Rice RE. 2002. Beyond Scholarship Reconsidered: Toward an enlarged vision of the scholarly work of faculty members. New Directions for Teaching and Learning, 90:7-17.

Rowland S, Byron C, Furedi F, Padfield N \& Smyth T. 1998. Turning academics into teachers? Teaching in Higher Education, 3(2): 133-141.

RSA (Republic of South Africa). 1996. National Education Policy Act, 1996 (Act 27 of 1996). Pretoria: Government Printers.

Ryan M, Campbell N \& Brigham C. 1999. Continuing professional education and interacting variables affecting behavioral change in practice: Instrument development and administration. The Journal of Continuing Education in Nursing, 30(4):168-175.

Sadler-Smith E, Allinson CW \& Hayes J. 2000. Learning preferences and cognitive style: Some implications for continuing professional development. Management Learning, $31(2): 239-256$.

Sandretto S, Kane R \& Heath C. 2002. Making the tacit explicit: A teaching intervention programme for early career academics. The International Journal for Academic Development, 7(2): 135-145. 
Schulman L. 1999. Professing educational scholarship. In: E Lagemann \& L Shulman (eds). Issues in Education Research: Problems and Possibilities. San Francisco, CA: Jossey-Bass. 159-165.

Shah SY. 1998. Professionalisation of Indian adult education. Asia Regional Literacy Forum [Online]. Available: http://www.literacyonline.org/products/ili/webdocs/shah.html [2004, 21 October].

Smyth R. 2003. Concepts of change: enhancing the practice of academic staff development in higher education. International Journal for Academic Development, 8(1/2):51-60.

Sorcinelli MD. 2002. New conceptions of scholarship for a new generation of faculty members. New Directions for Teaching and Learning, 90:41-48.

Sorcinelli MD, Austin AE, Eddy PL \& Beach AL. 2006. Creating the Future of Faculty Development: Learning From the Past, Understanding the Present. Bolton: Anker Publishing.

Taylor KL. 2005. Academic development as institutional leadership: An interplay of person, role, strategy, and institution. International Journal for Academic Development, 10(1):31-46.

Volbrecht T. 2003. The story of South African academic development in international perspective: have we lost the plot? South African Journal for Higher Education, 17(2):110-117.

Webb G. 1996. Understanding staff development. London: Society for research into Higher Education.

Wenger E. 1998. Communities of practice. Learning, meaning and identity. Cambridge: Cambridge University Press.

Wilson AL. 2000. Professional practice in the modern world. New Directions in Adult and Continuing Education, 86:71-79.

Zuber-Skerrit O. 1992. Professional development in higher education: A theoretical framework for action research. London: Kogan Page.

Zahorski KJ. 2002. Nurturing scholarship through holistic faculty development. New Directions for Teaching and Learning, 90:29-37. 